\title{
PANORAMA DAS DISSERTAÇÕES E TESES DEFENDIDAS NO PROGRAMA DE PÓS-GRADUAÇÃO EM EXTENSÃO RURAL DA UNIVERSIDADE FEDERAL DE VIÇOSA (1968 - 2017)
}

\author{
Isadora Moreira Ribeiro ${ }^{1}$ \\ Sheila Maria Doula ${ }^{2}$ \\ Marcelo Leles Romarco de Oliveira ${ }^{3}$
}

\begin{abstract}
RESUMO
O estudo apresenta um panorama das dissertações e teses defendidas no Programa de Pós-graduação em Extensão Rural da Universidade Federal de Viçosa, o mais antigo do Brasil, que completou 50 anos de implantação em 2018. Metodologicamente, utiliza-se a análise documental, classificando qualitativamente e quantitativamente os principais termos presentes nos títulos dos 538 trabalhos defendidos entre 1968 e 2017. Os resultados mostram o deslocamento de um projeto difusionista e produtivista de Extensão Rural para as reflexões acerca das consequências desse modelo, o que se acentua com a institucionalização da PNATER, em 2003. Com base no histórico institucional da Extensão Rural no Brasil, conclui-se que há uma inter-relação entre as pesquisas acadêmicas e as políticas públicas da área.
\end{abstract}

Palavras-chave: estado da arte, extensão rural, interdisciplinaridade.

\section{OVERVIEW OF DISSERTATIONS AND THESES PRESENTED IN THE POSTGRADUATE PROGRAM IN RURAL EXTENSION OF THE FEDERAL UNIVERSITY OF VIÇOSA (1968 - 2017)}

\begin{abstract}
The paper shows an overview of the dissertations and theses presented in the Postgraduate Program in Rural Extension of the Federal University of Viçosa, the first in Brazil, which completed 50 years in 2018. Documentary analysis is used as a method to classify qualitatively and quantitatively the main terms of the 538 titles presented between 1968 and 2017. The results indicate the change of a rural extension project based in diffusionism and productivism to the reflections about the consequences of this model. It is accentuated with the institutionalization of PNATER, in 2003. Based on the institutional history of the Rural Extension in Brazil,

${ }^{1}$ Graduada em Jornalismo (UFOP). Mestrado em Jornalismo (UFSC). E-mail: isadora.moreiraribeiro@gmail.com 2 (USP).Mestrado em Antropologia Social (USP). Doutorado em Antropologia Social (USP). Professora do Programa de Pós-Graduação em Extensão Rural (PPGER/UFV). E-mail: sheila@ufv.br

${ }^{3}$ Graduado em Administração (UFLA). Mestrado em Extensão Rural (UFV). Doutorado em Ciências Sociais em Desenvolvimento, Agricultura e Sociedade (UFRRJ). Professor do Programa de Pós-Graduação em Extensão Rural (PPGER/UFV). E-mail: marceloromarco@gmail.com
\end{abstract}


it is concluded that there is an interrelation between academic research and public policies in the area.

Keywords: interdisciplinarity, rural extension, state of art.

\section{INTRODUÇÃO}

O Programa de Pós-graduação em Extensão Rural (PPGER) da Universidade Federal de Viçosa (UFV) teve sua criação autorizada pelo Conselho Universitário em novembro de 1967 e deu início às suas atividades em março de 1968, com o curso de Mestrado, seguido pela instituição recente do Doutorado, em março de 2012 (PROGRAMA, 2018). Com mais de 50 anos de existência, o programa apresenta um total de 526 dissertações e 12 teses defendidas entre 1968 e 2017, o que denota a amplitude de sua produção acadêmica na área de Ciências Agrárias I, na qual está inserido conforme a classificação da Coordenação de Aperfeiçoamento de Pessoal de Nível Superior (CAPES).

Esse enquadramento institucional de caráter burocrático e de finalidade avaliativa não impossibilita, contudo, que se reconheça a interdisciplinaridade que permeia a Extensão Rural, tendo em vista que se "fundamenta teórica e metodologicamente em diversas subáreas das chamadas ciências sociais aplicadas e das ciências humanas, e aplica estes conhecimentos, no âmbito das ciências agrárias, aos problemas da extensão voltada ao meio rural" (DOULA; SOUZA, 2006, p. 282). Nesse sentido, os trabalhos acadêmicos e as práticas profissionais em Extensão Rural entrecruzam-se em diferentes subáreas do conhecimento, estando sujeitos às disposições de contextos espaço-temporais específicos e às dimensões processuais, institucionais e políticas que, conforme propõe Peixoto (2008), permitem delinear o termo.

Reconhecer essa conformação multidisciplinar da Extensão Rural faz-se necessário não só para fins de análise da produção acadêmica nesse campo de estudos. É também uma forma de superar a configuração engessada à aplicação técnica e às injunções de governos específicos que modela sua inserção na América Latina e que está imbricada na fundação do primeiro curso de pós-graduação específico na área no Brasil, o da UFV. Dessa forma, o percurso das pesquisas desenvolvidas no programa em cinco décadas é parte constituinte da história da Extensão Rural no país, o que evidencia a validade de uma observação do estado da arte dos conteúdos pesquisados, como se objetiva neste trabalho.

A prática de extensão aplicada ao meio rural teve origem nos Estados Unidos, com o fim da Guerra de Secessão (1861 - 1865) e a consequente transição do modelo de produção escravista para o mercantil (FONSECA, 1985). Nesse cenário, produtores se organizaram em associações para discutirem formas de adaptação às alterações produtivas decorrentes da guerra civil, o que foi posteriormente institucionalizado pelo governo estadunidense como "Trabalho Cooperativo de Extensão Rural", cujo propósito era difundir "conhecimentos úteis e práticos relacionados à agricultura, pecuária e economia doméstica para a adoção de modos mais eficientes na administração da propriedade rural e do lar" (FONSECA, 1985, p. 39).

As bases da Extensão Rural são, portanto, de natureza produtiva e agrícola, pautadas em uma comunicação transmissiva e linear do conhecimento científico e tecnológico para a população rural, denominada "modelo clássico" (FONSECA, 1985). Com o fim da Segunda Guerra Mundial, o "difusionismo produtivista", baseado na comunicação com finalidade persuasiva, passou a orientar 
os programas extensionistas que se expandiram pela América Latina sob influência dos Estados Unidos. Os pressupostos teóricos desse modelo remetem ao conceito de "difusão de inovações" de Everett Rogers (1983), publicado em livro homônimo em 1962. Diante da identificação da pobreza e da defasagem tecnológica das populações rurais latino-americanas, a extensão foi pensada para esses países "também como um projeto comunitário-educativo centrado na ambição de se converter num instrumento de solução para os problemas sociais rurais" (FONSECA, 1985, p. 48).

A concepção difusionista e as críticas a ela dirigidas, notadamente a abordagem pedagógico-comunicativa de Paulo Freire (1968), tiveram implicações predominantemente práticas, ainda que a extensão possa ser entendida como práxis. No entanto, como sistematiza Peixoto (2008), além dessa esfera processual, ligada à extensão como ação de transmissão e/ou troca de conhecimentos, pode-se delimitar a institucional, referente às organizações prestadoras dos serviços de Assistência Técnica e Extensão Rural (ATER), e a política, que remete ao posicionamento da extensão em planejamentos governamentais, sob a forma de políticas públicas. Embora o autor as apresente como conceituações diferentes para o termo extensão, entende-se que essas esferas devem ser interpretadas como categorias de finalidade analítica, uma vez que estão inter-relacionadas.

Nesse sentido, a opção por marcos institucionais e políticos para referenciar historicamente a produção acadêmica em Extensão Rural representa um recorte metodológico, e não uma compreensão limitada de extensão. Levam-se em conta, a partir das intervenções institucionais e legislativas do Estado, as próprias circunstâncias que favoreceram e nortearam a implantação do PPGER, cabendo ressaltar o pioneirismo da Escola Superior de Agricultura de Viçosa, atual UFV, no âmbito da ATER, o que se exemplifica pela realização da primeira Semana do Fazendeiro, em 1929 (PEIXOTO, 2008). Contudo, como assinala Peixoto (2008, p. 11), "o governo federal propunha, já na legislação de meados do século XIX, algumas ações de Extensão Rural, embora muito rudimentares ou implícitas em outras políticas públicas".

Oficialmente, foi com a implementação do Programa Piloto nos municípios de Santa Rita do Passa Quatro e São José do Rio Pardo (SP) e posterior fundação da Associação de Crédito e Assistência Rural (ACAR) em Minas Gerais (1948) que os serviços de Extensão Rural se institucionalizaram no Brasil (FONSECA, 1985). Como sinaliza Silva (2009, p. 28), "o paradigma da modernização tomou o lugar da missão civilizadora como ideologia de domínio Ocidental" no pós-guerra, o que estrutura a intervenção da American International Association for Economic and Social Development (AIA) no país, representada pela figura de Nelson Rockefeller.

A extensão institucionalizada pela ACAR teve como princípios a oferta de assistência técnica e de crédito supervisionado para pequenos agricultores (FONSECA, 1985). Entretanto, ainda que fundamentados no método estadunidense, os serviços prestados pela ACAR não advinham diretamente das universidades, mas sim das associações, como ressalta Peixoto (2008). Outra diferença foi a incorporação do crédito supervisionado ao modelo de extensão brasileiro, tendo em vista que, ao contrário do Brasil, a relação dos produtores com os bancos era habitual nos Estados Unidos (FONSECA, 1985).

A experiência da ACAR em Minas Gerais se expandiu por outras regiões do país no decorrer das décadas de 1950 e 1960, sendo criada, em 1956, a Associação Brasileira de Crédito e Assistência Rural (ABCAR), responsável por coordenar essas entidades originalmente "civis, sem fins lucrativos, que prestavam serviços de extensão rural e elaboração de projetos técnicos para obtenção de crédito junto aos agentes financeiros" (PEIXOTO, 2008, p. 18). A centralização pretendida pela 
ABCAR e o ideário desenvolvimentista e nacionalista que permearam o momento de sua criação manifestaram, no entanto, uma mudança do princípio privado para o estatal, levando às primeiras intervenções em direção a uma Política Nacional de Extensão Rural, segundo Fonseca (1985).

No início dos anos 1960, a AIA se retirou da direção da ACAR e da ABCAR, o que não representou o fim, mas sobretudo a intensificação do modelo de extensão importado com sua mediação, conforme esclarece Silva (2009). O autor aponta que "a intervenção do Estado sobre a extensão rural ampliou-se gradativamente, sem perder de vista o diálogo com a matriz norte-americana de modelo e financiamento" (SILVA, 2009, p. 195), o que descreve contextualmente a conformação extensionista a partir de 1964, com o golpe militar.

No governo ditatorial, criou-se o Sistema Nacional de Crédito Rural (1965), passando-se da oferta de crédito supervisionado para o orientado, de finalidade essencialmente produtiva (RODRIGUES, 1997). Refere-se a esse período, também, a instituição legal da Empresa Brasileira de Pesquisa Agropecuária (EMBRAPA), em 1972, e da Empresa Brasileira de Assistência Técnica e Extensão Rural (EMBRATER), em 1974, caracterizada como "pública, vinculada ao Ministério da Agricultura, com personalidade jurídica de direito privado e patrimônio próprio" (PEIXOTO, 2008, p. 23).

O regime militar também simbolizou o começo da pós-graduação em Extensão Rural no país, alocada no Departamento de Economia Rural (DER) da UFV, onde já se oferecia, desde 1961, a Pós-graduação em Economia Rural, em colaboração com a Universidade de Purdue, por meio de um convênio com a United States Agency for International Development (USAID) (DEPARTAMENTO, 2018). A construção do prédio que abriga o departamento também contou com o financiamento estadunidense, especificamente da Fundação Ford (idem), o que permite visualizar o papel da universidade pública no projeto de desenvolvimento econômico que já se esboçava nos anos precedentes. Nesse sentido, a Extensão Rural se institucionalizou como área de conhecimento paralelamente à estatização dos serviços de ATER e à federalização da então Universidade Rural do Estado de Minas Gerais (UREMG), em 1969 (UNIVERSIDADE, 2018). Esse projeto de extensão que se consolidou entre os anos 1950 e 1970 demarcou a transição de uma economia agrária para um "modelo de desenvolvimento rural baseado na difusão de pacotes tecnológicos modernizantes” (PEIXOTO, 2008, p. 24).

Inspirado nos moldes da Revolução Verde, esse processo de modernização do campo influiu diretamente nas pesquisas em ciências agrárias e estabeleceu o modelo predominante de financiamento público da extensão no Brasil, ainda que outras modalidades de fomento se apresentem em anos recentes. Com a redemocratização do país e a promulgação da Constituição de 1988, a política de desestatização levou à extinção da EMBRATER em 1990, no governo Collor (PEIXOTO, 2008). Nessa década, como notabiliza Peixoto (2008, p. 30), o Movimento dos Sem-Terra e os movimentos vinculados à Confederação Nacional de Trabalhadores da Agricultura (CONTAG) articularam-se na pauta pública, o que teve reverberação na legitimação de "estudos acadêmicos que propunham uma nova categoria de análise: o de agricultor familiar". Conforme o autor (idem), "o conceito de agricultura familiar influenciaria as políticas públicas no restante dos anos 90", tendo como marco o Programa Nacional de Fortalecimento da Agricultura Familiar (PRONAF), de 1996.

Em sequência cronológica, a retomada institucional do protagonismo estatal se efetivou em 2003, com a elaboração da Política Nacional de Assistência Técnica e Extensão Rural (PNATER), sob coordenação executiva, assim como o PRONAF, do Ministério do Desenvolvimento Agrário (MDA) (DIESEL; DIAS; NEUMANN, 2015). 
Incorporando em seu escopo a agricultura de base agroecológica ${ }^{4}$, a PNATER nasceu com um direcionamento para públicos variados, projetando uma dinâmica de atuação extensionista e de desenvolvimento diferente da praticada no século XX. De acordo com Diesel, Dias e Neumann (2015, p. 114), "de uma Ater caracterizada pelo apoio técnico e burocrático para uso do crédito, qualificadora do Pronaf, evolui-se para a reivindicação de uma Ater como política estruturante do desenvolvimento rural". No entanto, após mais de uma década, lacunas em relação às demandas dos múltiplos públicos abrangidos pela PNATER são evidentes (DINIZ; HESPANHOL, 2018).

Contemporaneamente, a instituição da Agência Nacional de Assistência Técnica e Extensão Rural (ANATER), em 2014, recuperou os princípios da tecnificação e da modernização atrelados à prática extensionista (ZARNOTT et al., 2015), o que reflete, de forma geral, a descontinuidade das políticas públicas para a Extensão Rural no Brasil, recentemente expressada através da extinção do MDA, em 2016. Frente às circunstâncias históricas que delimitam o percurso da Extensão Rural brasileira, a análise das pesquisas acadêmicas que se conformam nesse mesmo itinerário serve como indício dos reflexos e tensionamentos construídos na inter-relação entre as ações estatais e essa área de conhecimento. Com isso, busca-se compreender os conteúdos estudados no PPGER da UFV em 50 anos, com base histórica nas disposições institucionais e políticas.

\section{MATERIAL E MÉTODOS}

Para a aferição das 526 dissertações e 12 teses apresentadas junto ao PPGER foram verificadas três fontes, em ordem crescente de atualização dos dados: a primeira edição do Boletim de Pesquisas do Programa de Pós-graduação em Extensão Rural, Por Extenso (2009); a Lista de Dissertações (2017) elaborada pela Secretaria do PPGER; e o Repositório Institucional, Locus UFV. Considerandose o caráter secundário dessas fontes, utilizou-se como método a análise documental, caracterizada pelo emprego de técnicas da análise de conteúdo na codificação e categorização dos dados, conforme Pimentel (2001).

$\mathrm{Na}$ análise qualitativa, foram elaborados "quadros de termos-chave" (PIMENTEL, 2001) presentes nos títulos dos trabalhos, levando-se em conta que tais títulos constituem unidades sintáticas de amostragem, segundo Krippendorff (1980 apud BAUER, 2008). Com base na avaliação conjunta dos títulos, optou-se pela delimitação de grupos temáticos com os principais termos identificados, os quais foram organizados em cinco quadros correspondentes às décadas verificadas. Após essa classificação temática, mensurou-se a distribuição quantitativa dos trabalhos por grupo, ponderando-se o percentual de cada eixo temático em relação ao total de trabalhos de cada década. Essa etapa traduz a incidência dos temas categorizados com base no sentido das unidades sintáticas de amostra, não indicando a porcentagem de termos-chave. Não houve a utilização de softwares específicos nos processos analíticos.

\footnotetext{
${ }^{4} \mathrm{O}$ texto final da Lei № 12.188 , de 11 de janeiro de 2010, aprova o termo agricultura de base ecológica, o que não constitui enfoque deste trabalho.
} 


\section{RESULTADOS E DISCUSSÃO}

A categorização das unidades de amostra resultou na elaboração de cinco grupos temáticos, de acordo com a prioridade dada às dimensões técnico-aplicadas e institucionais (Grupo 1), econômico-financeiras (Grupo 2), socioantropológicas (Grupo 3), comunicativo-pedagógicas (Grupo 4) e ambientais (Grupo 5). Os dados qualitativos foram organizados em quadros correspondentes a cinco décadas (1968 - 1977 / 1978 - 1987 / 1988 - 1997 / 1998 - 2007 / 2008 - 2017), estando o Grupo 5 presente apenas nas duas últimas, o que se justifica pela importância adquirida pela pauta ambiental na agenda de pesquisa do século XXI.

$\mathrm{Na}$ primeira década analisada (1968 - 1977), foram defendidas 67 dissertações no PPGER. De maneira geral, os temas refletem a influência do modelo difusionista, oscilando entre pesquisas experimentais (de caráter zootécnico e agrícola) e pesquisas aplicadas (análises econômicas e financeiras). Do ponto de vista da prática extensionista, notam-se estudos centrados na comunicação para a adoção de tecnologias e análises sociais e psicológicas, estas indicando uma aproximação com o desenvolvimento de estratégias de persuasão dos produtores rurais. O crédito rural também é objeto de estudo, assim como a educação. Em relação aos públicos, não há uma segmentação que ultrapasse categorias mais generalizantes como trabalhadores, agricultores e proprietários. Observa-se a predominância de títulos que localizam geograficamente os casos investigados, os quais abrangem todas as regiões do país, ainda que majoritariamente a Sudeste, e dois outros países, Paraguai e Honduras. Para efeito de categorização, os principais termos apreendidos do material empírico são classificados no Quadro 1.

Quadro 1 - Termos categorizados entre 1968 e 1977.

\begin{tabular}{|c|l|}
\hline GRUPO 1 & $\begin{array}{l}\text { Emater; Extensão Rural; Inovações; Novas práticas; Novas tecnologias; } \\
\text { Práticas agrícolas; Reflorestamento; Sistemas de produção; Treinamento. }\end{array}$ \\
\hline GRUPO 2 & $\begin{array}{l}\text { Agroindústrias; Consumo; Cooperativas agrícolas; Crédito rural; Custo; } \\
\text { Empresas rurais; Incentivos fiscais; Mercado; Rentabilidade; Pequenas } \\
\text { empresas; Pequenos estabelecimentos agropecuários; Produtividade; } \\
\text { Transporte. }\end{array}$ \\
\hline GRUPO 3 & $\begin{array}{l}\text { Alienação; Classe; Desenvolvimento; Estratificação social; Mão de obra; } \\
\text { Modernização; Níveis habitacionais; Nível de vida; Pequenos agricultores; } \\
\text { Proprietários; Trabalhadores rurais. }\end{array}$ \\
\hline GRUPO 4 & $\begin{array}{l}\text { Analfabetismo; Comunicação; Discussão de grupo; Educação; Ensino; } \\
\text { Fontes de comunicação; Líderes de opinião; Rádio. }\end{array}$ \\
\hline
\end{tabular}

Com base na categorização periódica proposta por Rodrigues (1997), segundo a qual delimitam-se três tendências no processo evolutivo da extensão no Brasil, sendo estas o humanismo assistencialista (1948-1962), o difusionismo produtivista (1963-1984) e o humanismo crítico (1985-1989), o Quadro 1 aponta temporalmente para pesquisas inscritas no contexto de modernização do processo produtivo e de incentivo à adoção de tecnologias, com foco na categoria "produtor rural". Nota-se que os grupos 1 e 2 repercutem de maneira mais incidente a relação entre Extensão Rural e aplicação de conhecimentos no âmbito agrícola e econômico. O Grupo 2, especificamente, sugere o direcionamento das ações do Estado para os médios e grandes produtores, destacando-se a oferta de crédito orientado (RODRIGUES, 1997).

O Grupo 3 apresenta conceitos e categorias sociais mais próximos de vertentes teóricas críticas ao difusionismo produtivista. Conjugando-o ao Grupo 4, evidenciam-se estudos conectados ao humanismo assistencialista dos anos 
precedentes, dirigido a pequenos agricultores e ao nível familiar. Como assinala Rodrigues (1997, p. 125), a partir da política de extensão implantada pelo governo militar as ações de bem-estar deslocam-se do nível doméstico para "aspectos de nutrição, saúde e educação, utilizando a estrutura dos órgãos especializados já existentes e atuantes nestas áreas", o que tem reflexos na organização das equipes de extensionistas, que passam da proporção paritária entre profissionais de agronomia e economia doméstica para a progressiva redução destes. O Grupo 4 também permite visualizar a conexão entre extensão e comunicação, o que remete, no intervalo de tempo considerado, às teorias comunicacionais funcionalistas, relacionadas ao modelo de difusão de tecnologias, e aos meios de comunicação de massa, que se expandem pelo território nacional em função dos investimentos públicos nas estruturas de comunicação.

A segunda década considerada (1978 - 1987) compõe-se de 88 dissertações, com pesquisas relativas a todas as regiões brasileiras, além de duas latino-americanas, remetentes à Argentina e à Venezuela. As experimentações, as aplicações e a multidisciplinaridade relatadas na década anterior prevalecem, com destaque para a "difusão de inovações". Ainda que se mantenham semelhanças com o período precedente em termos de crédito e estratégias de comunicação, novos atores emergem, como os jovens e a família rural. Análises críticas da Extensão Rural também começam a aparecer, o que se conjuga com temas de pesquisa acerca da qualidade de vida, dos processos migratórios e da participação dos agricultores em organizações. Sobressaem neste ínterim investigações acerca dos projetos de ocupação das regiões interioranas financiados pelo regime militar, entre eles o Programa de Desenvolvimento da Região Centro-Oeste (POLOCENTRO), o Programa de Desenvolvimento de Áreas Integradas do Nordeste (POLONORDESTE) e o Programa Nacional para Aproveitamento de Várzeas Irrigáveis (PROVÁRZEAS). A categorização dos conceitos presentes nos títulos analisados é ordenada no Quadro 2.

Quadro 2 - Termos categorizados entre 1978 e 1987.

\begin{tabular}{|c|l|}
\hline GRUPO 1 & $\begin{array}{l}\text { Acar; Adoção tecnológica; Assistência técnica; Demonstração; Difusão de } \\
\text { tecnologia; Emater; Embrapa; Mecanização agrícola; Polocentro; } \\
\text { Polonordeste; Projetos de Extensão Rural; Provárzeas; Sistema de } \\
\text { extensão; Sistemas de produção; Tecnologia. }\end{array}$ \\
\hline GRUPO 2 & $\begin{array}{l}\text { Acumulação primitiva; Crédito rural; Comercialização; Cooperativas } \\
\text { agrícolas; Empresas agropecuárias; Indústria de alimentos; Preços mínimos; } \\
\text { Produtividade da terra; Renda; Renda familiar; Seguro Rural. }\end{array}$ \\
\hline GRUPO 3 & $\begin{array}{l}\text { Agricultores de baixa renda; Colonização; Estrutura agrária; Família Rural; } \\
\text { Jovens; Migração; Modernização; Organizações comunitárias; Papel da } \\
\text { mulher; Parceiros; Participação; Pequeno agricultor; Pequenos produtores; } \\
\text { Qualidade de vida; Relações de trabalho; Trabalho familiar. }\end{array}$ \\
\hline GRUPO 4 & Comunicação de massa; Educação; Escola rural; Líderes de opinião. \\
\hline
\end{tabular}

Os grupos 1 e 2 do Quadro 2 se aproximam dos preceitos difusonistas, com destaque para as políticas de crédito subsidiado e para a proeminência tecnológica em termos da grande produção. As pesquisas sobre os programas de colonização dirigida formulados pelo Estado (Grupo 1) podem ser relacionadas à emergência de estudos sobre colonização, estrutura agrária e migrações que aparecem no Grupo 3. Por essa direção, observa-se que as ações planejadas de desenvolvimento rural são absorvidas por dois tipos de investigações complementares: as que enfocam a avaliação das políticas e as que se voltam para os desdobramentos sociais dessas políticas. Essa constatação sugere que os estudos iniciais da pós-graduação em Extensão Rural tendem para a 
complementação e reforço do projeto da Revolução Verde, ao passo que os da segunda década já começam a sinalizar os efeitos contraditórios desse projeto.

Ainda que 0 Grupo 3 retome categorias sociais características do humanismo assistencialista, como família rural, jovens e mulheres, o projeto de redemocratização em curso nos anos 1980 permite associar tal retomada ao momento político e ao ideário do humanismo crítico demarcado por Rodrigues (1997), centrado na unidade familiar, na perspectiva dialógica e no estímulo à participação de pequenos e médios agricultores. De acordo com o autor, a partir de 1985 a extensão passa a incentivar "a organização autônoma desses agentes rurais através de sindicatos, associações e outras formas representativas não tuteladas" (RODRIGUES, 1997, p. 132). Diante da manutenção dos conteúdos do Grupo 4 e da pouca variação do Grupo 1 e do Grupo 2, depreende-se que o incremento temático do Grupo 3 prenuncia a inclinação para este perfil de estudos na década seguinte.

A década que se inicia com a promulgação da Constituição de 1988 (1988 1997) demonstra, através dos conteúdos das pesquisas acadêmicas, uma regressão da influência difusionista e a transição para pesquisas relacionadas a públicos mais específicos, com destaque à emergência da categoria agricultura familiar, que surge como uma noção centralizadora de demandas sociais diferenciadas e não referentes necessariamente a atores politicamente engajados (NAVARRO, 2001). As pesquisas experimentais e técnico-científicas não são tão evidentes quanto nas décadas anteriores, assim como os estudos sobre crédito e financiamento rural. A preocupação com sistemas de produção alternativos, políticas públicas e assentamentos da reforma agrária começa a sobressair-se, visualizando-se também a atenção às mídias em detrimento das estratégias de comunicação para a ação difusionista persuasiva, como se nota no Quadro 3.

Quadro 3 - Termos categorizados entre 1988 e 1997.

\begin{tabular}{|c|l|}
\hline \multirow{2}{*}{ GRUPO 1 } & $\begin{array}{l}\text { Acar; Adoção de tecnologia; Agricultura alternativa; Agricultura familiar; } \\
\text { Avaliação de Impactos Ambientais; Biotecnologia; Emater; Embrapa; } \\
\text { Extensão Rural; Método participativo; Pesquisa agrícola; Sistemas de } \\
\text { produção; Tecnologia; Tecnologia Alternativa; Políticas públicas; ONG. }\end{array}$ \\
\hline GRUPO 2 & Agroindústria; Comercialização; Cooperativa; Custos; Renda. \\
\hline & $\begin{array}{l}\text { Assalariados; Assentamentos; Assistencialismo; Colonização; Condições de } \\
\text { vida; Desenvolvimento; Desenvolvimento comunitário; Desenvolvimento } \\
\text { rural; Família rural; Gênero; Habitação; Ideário rural; Migração; } \\
\text { Modernidade; Modernização; Organização camponesa; Participação; } \\
\text { Pequenos agricultores; Pequenos proprietários; Pobreza; Qualidade de vida; } \\
\text { Representação social; Sindicatos; Sociabilidade; Trabalhadores rurais; } \\
\text { Tradição; Urbanização. }\end{array}$ \\
\hline GRUPO 4 & $\begin{array}{l}\text { Comunicação; Educação ambiental; Escola Família Agrícola; Escolas rurais; } \\
\text { Extensão universitária; Mediações; Mídia; Recepção; Telenovelas; TV. }\end{array}$ \\
\hline
\end{tabular}

Se considerados os grupos de enquadramento dos conteúdos, é visível, na terceira década, uma mudança qualitativa em processo, cabendo assinalar a diferenciação que a dimensão ambiental assume em relação aos grupos de classificação, o que se manifesta nos anos subsequentes. As 88 dissertações que representam este intervalo de tempo seguem distribuídas pelas regiões do país e, equiparadas às antecedentes, demarcam a transição de uma tendência difusionista para uma preocupação com públicos diversos, como se vê no Quadro 3.

No Grupo 1, os estudos sobre sistemas de produção alternativos demonstram as implicações do esgotamento do modelo de desenvolvimento adotado com base na Revolução Verde, o que se correlaciona ao decréscimo do Grupo 2, diretamente influenciado pelo crédito subsidiado e pela crise financeira dos 
anos 1980, e ao incremento do Grupo 3, no qual sobressaem pesquisas sobre desenvolvimento comunitário e local. Nessa conjuntura, o processo de descentralização dos serviços de extensão "valorizou crescentemente o 'local', no caso brasileiro, o município" (NAVARRO, 2001, p. 90). No Grupo 4, por sua vez, nota-se a continuidade das pesquisas pedagógicas e a influência dos estudos de comunicação latino-americanos, atentos às perspectivas da recepção e das mediações no consumo de produtos audiovisuais.

$\mathrm{Na}$ quarta década analisada (1998 - 2007), nota-se a particularização da pauta ambiental, cujos conceitos se conformam em um grupo específico (Grupo 5) no que se refere, principalmente, à dimensão jurídica e de movimentos sociais. A ampliação das discussões econômicas e dos atores e agentes sociais revela uma inserção crítica ao modelo excludente de modernização praticado nos anos precedentes e uma inter-relação com os desdobramentos do PRONAF e da PNATER. Numa visão panorâmica, a ideia de extensão agrícola e zootécnica é superada pelas demandas de ordem socioambiental, conservando-se a distribuição regional pelo país. Esse agendamento ambiental das pesquisas já é preconizado na década antecedente, com a realização da Conferência das Nações Unidas sobre o Meio Ambiente e o Desenvolvimento (Eco-92), refletindo o contexto global na passagem para o século XXI. Nos 122 títulos examinados, distinguem-se os enfoques participativos, a valorização patrimonial e do saber local, a questão agrária e discussões econômicas para além do crédito, o que pode ser averiguado no Quadro 4.

Quadro 4 - Termos categorizados entre 1998 e 2007.

\begin{tabular}{|c|l|}
\hline GRUPO 1 & $\begin{array}{l}\text { Agricultura familiar; Ater; Diagnóstico Rural Participativo; Difusão de } \\
\text { tecnologia; Emater; Embrapa; Inovação biotecnológica; Metodologias } \\
\text { participativas; Novas tecnologias; Ordenamento territorial; Pesquisa agrícola; } \\
\text { Pronaf; Reflorestamento; Sistemas agroflorestais; ONG's; Políticas públicas. }\end{array}$ \\
\hline GRUPO 2 & $\begin{array}{l}\text { Acumulação privada; Agroindústria; Agronegócio; Capital social; Economia } \\
\text { solidária; Pluriatividade; Turismo rural; Novo rural. }\end{array}$ \\
\hline GRUPO 3 & $\begin{array}{l}\text { Ação coletiva; Agricultores familiares; Associativismo; Assentamentos rurais; } \\
\text { Associações comunitárias; Comunidades camponesas; Conflito; Cultura } \\
\text { local; Desenvolvimento local; Envelhecimento; Gênero; Identidade; } \\
\text { Juventude; MST; Luta pela terra; Memória; Migração; Participação popular; } \\
\text { Patrimônio; Pescadores artesanais; Reforma agrária; Reforma aquática; } \\
\text { Religiosidade; Representações sociais; Ribeirinhos; Saber tradicional; } \\
\text { Trabalho escravo; Tradição; Violência. }\end{array}$ \\
\hline GRUPO 4 & $\begin{array}{l}\text { Comunicação; Comunicação organizacional; Educação ambiental; Escola } \\
\text { rural; Imprensa; Jornalismo rural; Mídia; TIC's. }\end{array}$ \\
\hline GRUPO 5 & $\begin{array}{l}\text { Agrotóxicos; Área de Proteção Ambiental; Barragens; Desenvolvimento } \\
\text { sustentável; Licenciamento ambiental; Meio ambiente; Mineração; Recursos } \\
\text { hídricos; Sustentabilidade; Transgênicos; Unidades de conservação. }\end{array}$ \\
\hline
\end{tabular}

Enquanto o Grupo 1 do Quadro 4 não apresenta alterações substanciais em comparação aos dez anos precedentes, o Grupo 2 incorpora discussões desvinculadas de uma abordagem exclusivamente setorial do rural, o que é sintetizado no conceito de pluriatividade, referência ao que Graziano da Silva (1997) define como "novo rural brasileiro". A segmentação de atores sociais evidenciada no Grupo 3 condiz com as demarcações de múltiplos públicos favorecidos pela PNATER, em que se incluem "agricultores familiares, assentados por programas de reforma agrária, extrativistas, ribeirinhos, indígenas, quilombolas, pescadores artesanais e aquiculturas, povos da floresta, seringueiros, e outros públicos definidos como beneficiários dos programas do MDA/SAF" (BRASIL, 2004, p. 7). No Grupo 4, 
as Tecnologias de Informação e Comunicação (TIC's) são o diferencial na equiparação com as décadas precedentes e o Grupo 5 concentra as consequências ambientais do modelo intensivo da Revolução Verde, emergindo a premissa do desenvolvimento sustentável, teoricamente amparado na tríade ecologia, economia e sociedade (VEIGA, 2010).

A última década (2008 - 2017) mantém-se em consonância com a anterior, sendo válido enfatizar o crescente número de estudos baseados em políticas públicas para o meio rural e para a soberania alimentar, visíveis no Quadro 5. A pluralidade de sujeitos sociais minoritários amplia-se gradativamente, ao passo que os estudos de ordem aplicada centram-se em sistemas de produção agropecuária alternativos aos intensivos. As Tecnologias de Informação e Comunicação (TICs) e as análises de redes, que evidenciam as potencialidades das mídias na comunicação extensionista (ANDRADE; TAUK SANTOS, 2015), são observáveis neste período, que compreende 161 dissertações e as primeiras 12 teses defendidas no PPGER. Pode-se depreender o movimento ascendente na produção acadêmica do programa, com conteúdos que refletem as injunções institucionais e legislativas a partir da PNATER.

Quadro 5 - Termos categorizados entre 2008 e 2017.

\begin{tabular}{|c|l|}
\hline GRUPO 1 & $\begin{array}{l}\text { Agroecologia; Agricultura camponesa; Agricultura familiar; Assessoria } \\
\text { Técnica Social e Ambiental à Reforma Agrária (ATES); Assistência técnica } \\
\text { privada; Ater; Emater; Estratégias de extensão rural; Extensão em } \\
\text { assentamentos rurais; ILPF; Incaper; Ordenamento territorial; Política de } \\
\text { extensão indígena; PAA; PNAE; Pnater; Pronaf; Técnicas participativas; } \\
\text { Tecnologia; Políticas públicas. }\end{array}$ \\
\hline GRUPO 2 & $\begin{array}{l}\text { Agronegócio; Capital social; Cooperativas; Cooperativismo de crédito } \\
\text { solidário; Economia solidária; Mercados; Pluriatividade; Turismo rural. }\end{array}$ \\
\hline GRUPO 3 & $\begin{array}{l}\text { Ação coletiva; Aposentadoria rural; Artesanato; Assentamento; } \\
\text { Comunidades indígenas; Conflitos; Crianças rurais; Cultura; } \\
\text { Desenvolvimento local; Desenvolvimento rural; Desenvolvimento territorial; } \\
\text { Família; Gênero; Identidades; Juventude rural; Meios de vida; Memória; } \\
\text { Migração; Modernidade; Organizações associativas; Patrimônio; } \\
\text { Pescadores artesanais; Populações tradicionais; Quilombolas; Redes } \\
\text { sociais; Reforma agrária; Representações sociais; Ruralidade; } \\
\text { Rurbanidade; Saber-fazer artesanal; Soberania alimentar; Sociabilidade; } \\
\text { Sucessão; Tradição. }\end{array}$ \\
\hline GRUPO 4 & $\begin{array}{l}\text { Comunicação; Educação ambiental; Escolas Famílias Agrícolas; Escola } \\
\text { rural; Imprensa; Mídia; TIC's. }\end{array}$ \\
\hline GRUPO 5 & $\begin{array}{l}\text { Agrotóxicos; Barragens; Conflitos ambientais; Desenvolvimento rural } \\
\text { sustentável; Licenciamento ambiental; MAB; Mineração; Novo Código } \\
\text { Florestal; Políticas ambientais; Reserva extrativista; Sustentabilidade. }\end{array}$ \\
\hline
\end{tabular}

O Grupo 1 do Quadro 5 demonstra a variação na natureza de financiamento e de destinação dos serviços de assistência técnica e Extensão Rural, com distinção do financiamento privado, incentivado pelo Banco Mundial e pela FAO desde os anos 1990 (DA ROS, 2012). Observa-se também a prevalência de pesquisas sobre políticas públicas específicas, o que se aproxima das primeiras décadas, no sentido do foco nas intervenções do Estado direcionadas ao âmbito rural. No Grupo 2, o deslocamento em relação às políticas de crédito subsidiadas pelo Estado se consolida, distinguindo-se o papel dos mercados institucionalmente demarcados pela PNATER. No Grupo 3, persiste a multiplicidade de públicos e as perspectivas que ressaltam as práticas tradicionais e a imaterialidade dos patrimônios socioculturais construídos no rural. O conceito de desenvolvimento territorial e o tema da soberania alimentar surgem conectados às políticas recentes para o meio 
rural. Por sua vez, os grupos 4 e 5 conservam-se em consonância com a década anterior.

Do ponto de vista quantitativo, a Tabela 1 demonstra a maior concentração de estudos de perfil técnico-aplicado ou institucional nas primeiras décadas, assim como as pesquisas de caráter econômico-financeiro, por sua vez progressivamente decrescentes. Os estudos de angulação predominantemente socioantropológica se destacam em ascendência no decorrer do tempo, enquanto os comunicativopedagógicos e os ambientais se mantêm sem oscilações significativas.

Tabela 1 - Distribuição quantitativa dos grupos.

\section{PORCENTAGEM / № DE TRABALHOS / DÉCADA}

\begin{tabular}{|c|c|c|c|c|c|}
\hline & $1968-1977$ & $1978-1987$ & $1988-1997$ & $1998-2007$ & $2008-2017$ \\
\hline GRUPO 1 & $34,33 \%$ & $43,18 \%$ & $45,46 \%$ & $13,11 \%$ & $21,39 \%$ \\
\hline GRUPO 2 & $35,82 \%$ & $17,05 \%$ & $7,95 \%$ & $9,02 \%$ & $9,83 \%$ \\
\hline GRUPO 3 & $19,40 \%$ & $31,82 \%$ & $30,69 \%$ & $42,62 \%$ & $39,88 \%$ \\
\hline GRUPO 4 & $10,45 \%$ & $7,95 \%$ & $15,90 \%$ & $18,85 \%$ & $15,03 \%$ \\
\hline GRUPO 5 & - & - & - & $16,40 \%$ & $13,87 \%$ \\
\hline $\begin{array}{l}\text { TOTAL DE } \\
\text { TRABALHOS }\end{array}$ & 67 & 88 & 88 & 122 & 173 \\
\hline
\end{tabular}

A observação conjunta da distribuição quantitativa dos grupos no intervalo de tempo permite inferir que as pesquisas localizadas nos grupos 1 e 3 constituem os principais temas de estudo, equivalendo respectivamente a $28,62 \%$ e $35,13 \%$ do total de 538 títulos analisados. Na sequência, o Grupo 4 representa 14,31\% da totalidade da amostra, seguido pelo Grupo 2, com 13,76\%, e pelo Grupo 5, como $8,18 \%$. Este, cabe relembrar, referente apenas aos 20 anos finais da análise.

\section{CONCLUSÕES}

A análise dos conteúdos explicitados nos títulos das dissertações e teses defendidas no PPGER da UFV entre 1968 e 2017 aponta para o deslocamento de um projeto prático-político de Extensão Rural para as reflexões sobre as consequências desse projeto. Levando-se em conta essas considerações, as pesquisas das duas primeiras décadas (1968 - 1977 / 1978 - 1987) demarcam-se em um plano de desenvolvimento econômico em que a Extensão Rural é vista como instrumento e processo comunicacional-persuasivo e pedagógico com a finalidade de modernização do campo e difusão de tecnologias para os pequenos agricultores, o que se reflete em estudos aplicados e minoritariamente críticos aos difusionismo.

A terceira década (1988 - 1997), além de representar a transição democrática do país e a desconstrução dos serviços públicos de extensão, configura-se como passagem para estudos críticos ao contexto precedente, direcionando-se aos atores excluídos pelo processo de modernização e às consequências ambientais do modelo inspirado na Revolução Verde. Nas duas últimas décadas (1998 - 2007 / 2008 - 2017), nota-se que a retomada de uma 
política pública federal de ATER a partir de 2003 tem reverberações no campo acadêmico e na compreensão da prática extensionista, a qual se desloca para a operacionalização de programas específicos incluídos nessa política.

Nesse percurso temporal, percebe-se que a pesquisa em Extensão Rural está predominantemente correlacionada às instâncias institucionais e políticas, conforme demarcação de Peixoto (2008). Nesse sentido, a dimensão prática aparece como aplicação das disposições institucionais ou como proposição de modelos alternativos com a finalidade de que se institucionalizem. A investigação acadêmica demonstra, portanto, a preocupação com a articulação prévia de intervenções sobre o rural e com a análise de ações já implantadas, o que representa a premissa mais ampla de desenvolvimento rural, segundo conceituação de Navarro (2001).

Ainda que as dimensões socioculturais adquiram relevância com o passar dos anos, a justificativa ampara-se mais nos desdobramentos da PNATER do que na ampliação do escopo aplicado da extensão, o que possibilitaria vislumbrar as populações rurais em circunstâncias que extrapolam os limites mediadores do Estado. É fato que o ensino da Extensão Rural - o que inclui formação dos professores, projetos de pesquisa em desenvolvimento e área de graduação dos alunos - interliga-se ao perfil das pesquisas desenvolvidas, assim como as disposições de sua área de avaliação, Ciências Agrárias I. Contudo, a delimitação acadêmica do PPGER pressupõe superar uma redutibilidade contemplada por níveis profissionais de pós-graduação.

Frente ao tracejo desse panorama, assinalado como objetivo deste trabalho, infere-se que, apesar dos diferentes norteamentos que acompanham a pesquisa em Extensão em cinco décadas, a base estatal, acionada no nível da difusão de inovações ou no contexto cíclico das políticas públicas, ainda é estruturante. Por um lado, reconhecido o papel dos extensionistas públicos na operacionalização das intervenções do Estado, emergem indagações no âmbito do direcionamento da academia para esses profissionais. Por outro, as esferas não públicas que também atravessam o escopo da Extensão Rural surgem como lacunas e desafios à pesquisa acadêmica na área.

Conclui-se, portanto, que o agendamento em relação ao debate público é característico nas pesquisas e na prática extensionista, uma vez que a interdisciplinaridade que as permeia não permite falar em um campo e em um referencial teórico específico da Extensão Rural, embora não seja esse o objeto desta discussão. Assumindo-se essa inter-relação entre Extensão Rural e determinantes legislativos e institucionais, pode-se presumir que a institucionalização da ANATER e a exclusão do MDA terão repercussões nos estudos desenvolvidos nos próximos anos, com atenção às pesquisas inscritas no perfil crítico quanto ao ressurgimento da orientação tecnicista em detrimento da pulverização de públicos minoritários anteriormente beneficiados pela PNATER.

\section{AGRADECIMENTOS}

O presente trabalho foi realizado com apoio da Coordenação de Aperfeiçoamento de Pessoal de Nível Superior - Brasil (CAPES) - Código de Financiamento 001.

\section{REFERÊNCIAS}

ANDRADE, B. O.; TAUK SANTOS; M. S. Extensão rural e cibercultura: o facebook como ferramenta de promoção da Política Nacional de Assistência Técnica e Extensão Rural. Extensão Rural, Santa Maria, v. 22, n. 3, p. 29-47, jul./set. 2015. 
Disponível em: https://periodicos.ufsm.br/extensaorural/article/view/10014/pdf. Acesso em: 7 jan. 2020.

BAUER, M. W. Análise de conteúdo clássica: uma revisão. In: BAUER, M. W.; GASKELL, G. Pesquisa qualitativa com texto, imagem e som: um manual prático. 7. ed. Petrópolis: Vozes, 2008. p. 189-217.

BRASIL. Ministério do Desenvolvimento Agrário. Política Nacional de Assistência

Técnica e Extensão Rural. Brasília, 2004. Disponível em: http://www.ipea.gov.br/participacao/images/pdfs/conferencias/2CNDRSS/2cndrss\%2 Opoltica_nacional.pdf. Acesso em: 9 jan. 2019.

DA ROS, C. A. Gênese, desenvolvimento, crise e reformas nos serviços públicos de extensão rural durante a década de 1990. Mundo Agrario, v. 13, n. 25, p. 1-33, 2012.

Disponível

em: http://sedici.unlp.edu.ar/bitstream/handle/10915/26261/04+G\%EAnese,+desenvolvim ento,+crise. pdf;jsessionid=1FD89D96700ECAFD95A8B47F2B35A615? sequence $=1$. Acesso em: 9 jan. 2019.

DEPARTAMENTO de Economia Rural. Histórico. Disponível em: http://www.der.ufv.br/?page_id=540. Acesso em: 31 maio 2018.

DIESEL, V.; DIAS, M. M.; NEUMANN, P. S. Pnater (2004-2014): da concepção à materialização. In.: GRISA, C.; SCHNEIDER, S. (Orgs.). Políticas públicas de desenvolvimento rural no Brasil. Porto Alegre: Editora da UFRGS, 2015. p. 107 128.

DINIZ, R. F.; HESPANHOL, A. N. Reestruturação, reorientação e renovação do serviço extensionista no Brasil: a (difícil) implementação da Política Nacional de Assistência Técnica e Extensão Rural (PNATER). Extensão Rural, Santa Maria, v. 25, n. 2, p. 7-30, abr./jun. 2018. Disponível em: https://periodicos.ufsm.br/extensaorural/article/view/33174/pdf. Acesso em: 7 jan. 2020.

DOULA, S. M.; SOUZA, R. S. de. A Pós-Graduação em Extensão Rural no Brasil: perfil, dificuldades e perspectivas. Revista Brasileira de Pós-Graduação - RBPG, Brasília, v. 3, n. 6, p. 282-299, dez. 2006. Disponível em: http://ojs.rbpg.capes.gov.br/index.php/rbpg/article/view/111/105. Acesso em: 31 maio 2018.

FONSECA, M. T. L. Extensão Rural no Brasil: um projeto educativo para o capital. São Paulo: Edições Loyola, 1985.

FREIRE, P. Extensão ou comunicação? Rio de Janeiro: Paz e Terra, 1983.

GRAZIANO DA SILVA, J. O novo rural brasileiro. Nova Economia, Belo Horizonte, v. $7, \quad$ n. $1, \quad$ p. 43-81,1997. Disponível em: https://revistas.face.ufmg.br/index.php/novaeconomia/article/view/2253/1193. Acesso em: 9 jan. 2019. 
NAVARRO, Z. Desenvolvimento rural no Brasil: os limites do passado e os caminhos do futuro. Estudos Avançados, São Paulo, v. 15, n. 43, p. 83-100, 2001. Disponível em: http://www.scielo.br/pdf/ea/v15n43/v15n43a09.pdf. Acesso em: 9 jan. 2019.

PEIXOTO, M. Extensão Rural no Brasil: uma abordagem histórica da legislação. In: CONLEG - Consultoria Legislativa do Senado Federal. Textos para Discussão, Brasília, v. 48, p. 1-47, $2008 . \quad$ Disponível em: https://www12.senado.leg.br/publicacoes/estudos-legislativos/tipos-deestudos/textos-para-discussao/td-48-extensao-rural-no-brasil-uma-abordagemhistorica-da-legislacao. Acesso em: 9 jan. 2019.

PIMENTEL, A. O método da análise documental: seu uso numa pesquisa historiográfica. Cadernos de Pesquisa, n. 114, p. 179-195, 2001. Disponível em: http://www.scielo.br/pdf/cp/n114/a08n114. Acesso em: 9 jan. 2019.

POR EXTENSO. Boletim de Pesquisas do Programa de Pós-graduação em Extensão Rural. Viçosa, UFV, DER, 2009.

PROGRAMA de Pós-graduação em Extensão Rural. Histórico. Disponível em: http://www.posextensaorural.ufv.br/?page_id=49. Acesso em: 31 maio 2018.

RODRIGUES, C. M. Conceito de seletividade de políticas públicas e sua aplicação no contexto da política de extensão rural no Brasil. Cadernos de Ciência \& Tecnologia, Brasília, v. 14, n. 1, p. 113-154, 1997. Disponível em: https://seer.sct.embrapa.br/index.php/cct/article/view/8963/5075. Acesso em: 9 jan. 2019.

ROGERS, E. M. Diffusion of innovations. New York: The Free Press, 1983.

SECRETARIA do Programa de Pós-graduação em Extensão Rural da Universidade Federal de Viçosa. Lista de Dissertações. 2017. Disponível em: http://www.posextensaorural.ufv.br/wp-content/uploads/2012/02/Lista-DissertaçõesPPGEX.pdf. Acesso em: 3 jun. 2018.

SILVA, C. M. Agricultura e Cooperação Internacional: a atuação da American International Association for Economic and Social Development (AIA) e os programas de modernização do Brasil (1946 - 1961). 2009. 225 f. Tese (Doutorado em História das Ciências e da Saúde) - Casa de Oswaldo Cruz / Fiocruz, Rio de Janeiro, 2009. Disponível em: https://www.arca.fiocruz.br/bitstream/icict/15974/2/67.pdf. Acesso em: 9 jan. 2019.

UNIVERSIDADE Federal de Viçosa. História. Disponível em: http://www.portal.ufv.br/crp/?page_id=55. Acesso em: 31 maio. 2018.

UNIVERSIDADE Federal de Viçosa. Locus UFV. Disponível em: http://www.locus.ufv.br/handle/123456789/168/browse. Acesso em: 3 jun. 2018.

VEIGA, J. E. Desenvolvimento sustentável: o desafio do século XXI. Rio de Janeiro: Garamond, 2010.

ZARNOTT, A. V. et al. Avanços e retrocessos nas políticas de extensão rural: análise crítica sobre a ANATER. In: 53을 CONGRESSO DA SOCIEDADE 
BRASILEIRA DE ECONOMIA, ADMINISTRAÇÃO E SOCIOLOGIA RURAL, 53., 2015. João Pessoa. Anais... João Pessoa: UFPB, 2015, p. 1-20. Disponível em: http://icongresso.itarget.com.br/tra/arquivos/ser.5/1/5277.pdf. Acesso em: 31 maio 2018. 